\title{
Aggression is suppressed by acute stress but induced by chronic stress: Immobilization effects on aggression, hormones, and cortical $5-\mathrm{HT}_{1 \mathrm{~B}} /$ striatal dopamine $\mathrm{D}_{2}$ receptor density
}

\author{
Laurel R. Yohe • Hideo Suzuki • Louis R. Lucas
}

Published online: 4 May 2012

(C) Psychonomic Society, Inc. 2012

\begin{abstract}
Although it has been established by a number of investigators that a variety of stressors are associated with the induction of aggressive behavior, two specific issues remain unanswered. First, it is unclear whether the contexts surrounding stressors (e.g., stressor length and chance of winning over opponents) change outcomes regarding aggressive behavior. Second, if a relationship exists between stress and aggressive behavior, altered levels of stressrelated hormone (e.g., corticosterone [CORT]), as well as aggression-related biomarkers (e.g., testosterone [T], density of prefronto-cortical 5- $\mathrm{HT}_{1 \mathrm{~B}}$ receptor and striatal dopamine $\mathrm{D}_{2}$ receptor $[\mathrm{D} 2 \mathrm{r}]$ ) may contribute to changes in aggressive behavior. Thus, we examined how immobilization (with a 1-, 5-, or 10-day exposure) would impact (1) a longitudinal course of aggression toward different-sized opponents, (2) levels of CORT and T, and (3) densities of $5-\mathrm{HT}_{1 \mathrm{~B}}$ receptor $(5-\mathrm{HT} 1 \mathrm{Br})$ in the prefrontal cortex $(\mathrm{PFC})$ and $\mathrm{D} 2 \mathrm{r}$ in the striatum. It was found that, regardless of small or large opponents, a single 2-h exposure to immobilization reduced aggressive behavior (stress-suppressed aggression) over time, whereas repeated (10-day) exposure to immobilization escalated aggressive behavior (stress-induced aggression). These stress effects persisted up to 1 week of recovery from immobilization stress. Moreover, immobilized rats demonstrated elevated levels of $\mathrm{T}$, but not
\end{abstract}

L. R. Yohe $\cdot$ L. R. Lucas $(\bowtie)$

Department of Biology, Loyola University Chicago,

1032 W Sheridan Rd.,

Chicago, IL 60660, USA

e-mail: 1lucas2@luc.edu

H. Suzuki

Department of Psychiatry,

Washington University School of Medicine,

660 S Euclid Ave.,

St. Louis, MO 63110, USA
CORT, as compared with controls. Finally, acute immobilization altered D2r densities in the shell of the nucleus accumbens, and chronic immobilization changed 5-HT1Br in the PFC, including the downregulation of 5-HT1Br densities in the right prelimbic and orbitolateral cortices. The potential relationships among stress, aggression, and 5$\mathrm{HT} 1 \mathrm{Br} / \mathrm{D} 2 \mathrm{r}$ roles are discussed.

Keywords Animal models · Corticosterone · Dopamine Serotonin $\cdot$ Stress-induced aggression

A number of animal studies have addressed the hypothesis that aggressive behavior is induced by various stress paradigms (Olivier \& Young, 2002), such as footshock (Eichelman \& Barchas, 1975; Zebrowska-Lupina, Ossowska, \& Klenk-Majewska, 1991), social stress (Tamashiro, Nguyen, \& Sakai, 2005), social instigation (da Veiga, Miczek, Lucion, \& de Almeida, 2011; Fish, Faccidomo, \& Miczek, 1999), nonrewarding frustration (de Almeida \& Miczek, 2002), social isolation (Malick, 1979; Valzelli, 1985), restraint (Wood, Young, Reagan, \& McEwen, 2003), and immobilization (Wood, Norris, Waters, Stoldt, \& McEwen, 2008). However, stress does not always escalate aggressive behavior; rather, it appears to be context dependent. For example, animals in a social stress paradigm increase aggressive behavior only when they are dominant in a social hierarchy (Blanchard \& Blanchard, 1990; Blanchard et al., 1995; Tamashiro et al., 2004). Or, subordinate animals can also become more aggressive only if their opponent is younger and smaller than themselves (Delville, Melloni, \& Ferris, 1998; Wommack \& Delville, 2003). Some other studies have revealed that aggressive behavior is induced only by repeated exposure to stress (Wood et al., 2008; Wood et al., 2003). Taken together, the relationship between stress and aggression seems to be 
modulated by a behavioral history of social defeats (e.g., experiences of defeating opponents or being defeated by others), the chance of winning over an opponent (e.g., because of the physical size of an opponent), and a different amount of stress exposure (e.g., acute vs. chronic stress). Despite the potential importance of these contextual modulators in stress-induced aggression, to our knowledge, no study has comprehensively examined how stress-induced aggressive behavior may be altered by a behavioral history of social defeats against different-sized opponents following acute or chronic exposure to stress.

Although there is a deficit in understanding the biological mechanisms underlying stress-induced aggression, previous work has identified some biological markers relating to stress or aggressive behavior per se. A common biomarker of stress is the glucocorticoid corticosterone (CORT in rodents), and stress activates the hypothalamic-pituitaryadrenal axis and releases CORT (Jacobson \& Sapolsky, 1991). Interestingly, there is speculation that an increase in glucocorticoids due to stress mutually influences an increased sensitivity to aggression-promoting factors (e.g., frustration), creating a "vicious cycle" between stress and aggression (Craig, 2007). Indeed, the electrical stimulation of an "aggressive area" in the hypothalamus increases plasma CORT levels (Kruk, Halasz, Meelis, \& Haller, 2004); conversely, acute administration of CORT escalates aggressive behavior (Kruk et al., 2004). These findings suggest that CORT responds to stress and may spread its effects over aggressive behavior (although few studies have directly investigated the relation between CORT and stress-induced aggression).

Related to biomarkers of aggressive behavior, testosterone $(\mathrm{T})$ seems to play an important role in aggression, given that effects of $\mathrm{T}$ on gender and age differences in aggression have been suggested (Rada, Kellner, \& Winslow, 1976; Van Goozen, 2005). In addition to T, neurochemical systems, especially serotonergic and dopaminergic systems, are commonly associated with aggressive behavior (de Almeida, Ferrari, Parmigiani, \& Miczek, 2005). For example, 5$\mathrm{HT}_{1 \mathrm{~B}}$ receptor $(5-\mathrm{HT} 1 \mathrm{Br})$ function contributes to the control of aggressive behavior in rodents (de Boer \& Koolhaas, 2005; Lopez, Vazquez, Chalmers, \& Watson, 1997; Olivier $\&$ van Oorschot, 2005; Saudou et al., 1994). Furthermore, decreased levels of 5-HT neurotransmission, specifically located in the prefrontal cortex (PFC), and increased levels of dopamine in the nucleus accumbens are promoted after aggression (van Erp \& Miczek, 2000). Finally, alterations in $\mathrm{D} 2 \mathrm{r}$ binding in the striatum may be related to aggressiveness (Suzuki, Han, \& Lucas, 2010a). Importantly, striatal D2r binding is also changed as a consequence of stress, such as subordination stress (Lucas et al., 2004) and immobilization stress (Lucas, Wang, McCall, \& McEwen, 2007), suggesting that striatal D2r may be associated not only with aggression, but also with stress. However, no study has directly examined whether T, prefronto-cortical 5-HT1Br, and/or striatal D2r are altered by stress-induced aggression.

Taken together, stress appears to be related to CORT, while aggressive behavior is related to $\mathrm{T}$, prefronto-cortical $5-\mathrm{HT} 1 \mathrm{Br}$, and striatal D2r. Yet it still remains unclear whether these four biomarkers are associated with stress-related aggression. The aim of the present study was to examine whether the effects of chronic stress alter behavioral, hormonal, and neurochemical systems regarding aggression, using acute/chronic immobilization stress. Specifically, it was hypothesized that aggressive behavior, CORT, T, prefronto-cortical 5-HT1Br density, and/or striatal D2r density would be changed by repeated exposure to immobilization stress. Furthermore, as described above, because stressinduced aggression might be affected by the size of an opponent, we tested how different weights of opponents change stress-induced aggression. Also, our study set out to examine the effect of a recovery period after immobilization on aggression by tracking the levels of aggressive behavior across time, which is a concept other studies have failed to address. This allowed us to begin to understand how a behavioral history of social defeats following immobilization stress might influence aggressive behavior, such that previous experience of winning or losing immediately after stress might encourage or discourage individuals to maintain aggression levels on follow-up behavioral tests. We expected that stress-induced aggression would be more escalated over time when animal subjects encountered a small or equal-sized opponent (because of high likelihood of winning over time), whereas aggression would be reduced against a larger sized opponent over time.

\section{Method}

Animals

Male Sprague-Dawley rats obtained from Charles River (Portage, MI; $N=108$ ) were bred in our animal care facilities (ACF). They were kept on a 12:12-h light:dark cycle (lights on/off at $0700 \mathrm{~h} / 1900 \mathrm{~h}$ ) and were given ad lib conditions (e.g., pellet-typed, LabDiet 5001 Rodent Diet [Southern Agriculture, Tulsa, OK], temperature $=21^{\circ}-22^{\circ}$ $\mathrm{C}$, humidity $=30 \%-60 \%$ ), approved by the Institutional Animal Care and Use Committee at Loyola University Chicago. They were also group-housed (3-6 cohabitants) in a clear, plastic cage $(47 \times 25.5 \times 21.5 \mathrm{~cm})$ with bedding until the desired experimental weight $(\sim 250 \mathrm{~g})$ was reached.

Then rats were assigned to either immobilization conditions $(n=54)$ or nonimmobilization control conditions $(n=54)$. Within the immobilization conditions, 54 animals were subjected to one of three different amounts of 
exposure to immobilization stress: 1-day stress exposure $(n=18)$, 5-day stress exposure $(n=18)$, and 10-day stress exposure $(n=18)$. However, 2 animals were removed from all analyses due to the fact that the subjects managed to escape during immobilization sessions. The other 54 controls were assigned to each of the following control conditions: 1day nonstress exposure $(n=18)$, 5-day nonstress exposure $(n=18)$, and 10-day nonstress exposure $(n=18)$.

\section{Experimental procedure}

Figure 1 summarizes a flow of our experiments. Immobilization bags were cut into a triangular shape and sealed with a cut at the tip to allow the nose of the rats to poke out for breathing. At the time of a stress exposure session (started at $1900 \mathrm{~h}$ ), both the immobilized group and nonimmobilized controls were transported to a separate room in the ACF. Body weight and time at which immobilization was administered were recorded for each rat. Then, for the immobilized groups, the rats were placed head first into a plastic immobilization bag (ULINE, 6 mil, Chicago) and tapeclosed for $2 \mathrm{~h}$. Once placed in the immobilization bag, the rat was placed into a new plastic cage with bedding. Control rats were not placed into an immobilization bag; instead, they were handled briefly and transferred to a new cage for $2 \mathrm{~h}$. All exposure sessions were run with the lights off, and no food and water were provided to either the immobilized or the nonimmobilized group.
Stressed rats were released from their immobilization bag $2 \mathrm{~h}$ after the stress exposure session, and both the immobilized and nonimmobilized groups were returned to their individual-housed home cage under ad lib condition. If the rats were assigned to a 5-day stress/nonstress exposure or a 10-day stress/nonstress exposure, the procedure above was repeated for the respective amount of days.

After all stress exposure sessions had been administered, the aggression of each rat was assessed at 1-day, 2-day, and 7-day postexposure to stress/nonstress (for details, see the next section). During these aggression assessments, the subjects encountered either a smaller $(150-250 \mathrm{~g})$ or larger $(<350 \mathrm{~g})$ naïve opponent rat. Immediately following the third assessment (i.e., 7-day postexposure to stress/nonstress), the rats were decapitated for further hormonal and neurochemical assessments.

\section{Measurement of aggression}

Both the immobilized and nonimmobilized groups underwent three behavioral screening tests to measure their aggressive behavior, starting at $1900 \mathrm{~h}$. Each rat was paired with a naïve opponent rat for $10 \mathrm{~min}$ within a new cage under a red light condition. Each behavioral test was videotaped, and a trained experimenter scored aggressive and defensive behaviors of rat subjects. Both aggressive and defensive behaviors were measured using established behavioral markers (Suzuki \& Lucas, 2010). Aggressive behavior
Fig. 1 Timeline of each immobilization experiment. Dashed boxes indicate immobilization sessions lasting $2 \mathrm{~h}$. After the completion of the immobilization portion, subjects underwent three screening tests, indicated by the arrow boxes. All subjects were screened for aggression 1 day, 2 days, and 7 days after the last immobilization session
I-d Immobilization/Non-Immobilization

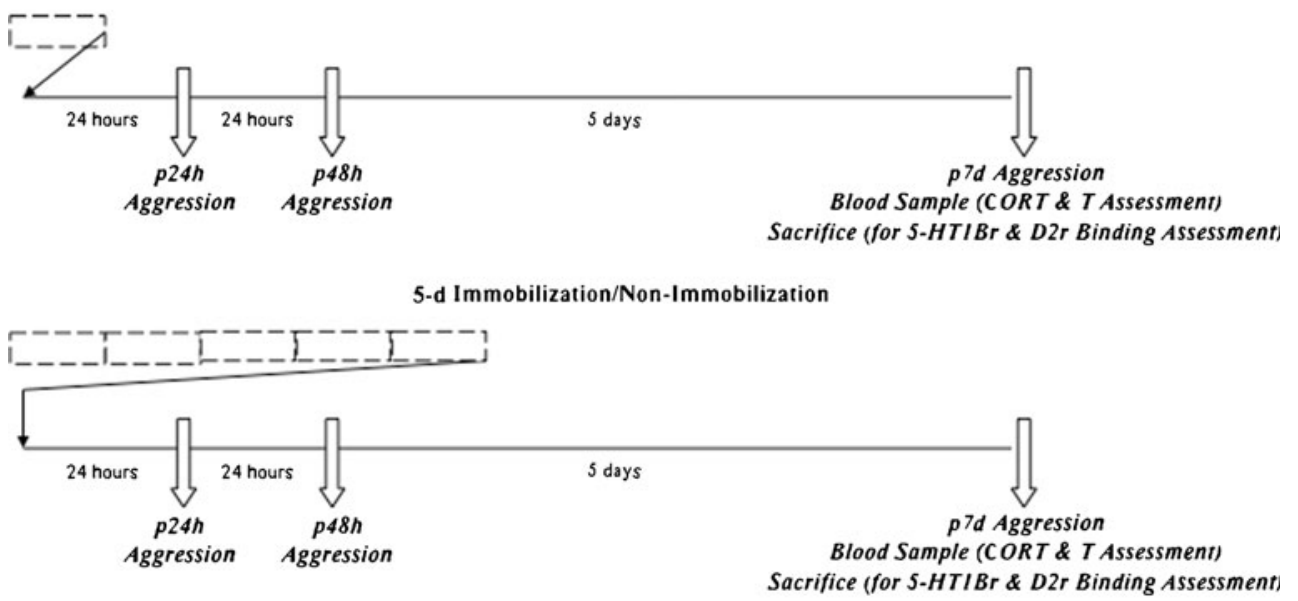

10-d Immobilization/Non-Immobilization

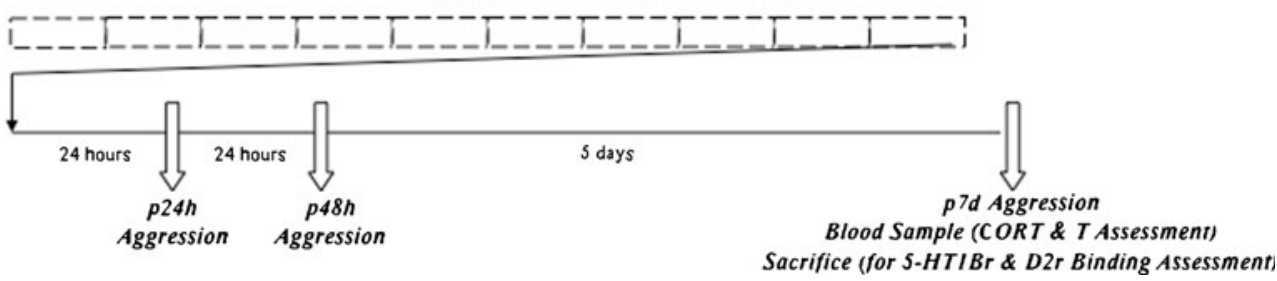


was quantified by counting the total number of seconds during which the rat subject performed the following actions: attack, threat (offensive block), aggressive posture, allogrooming (aggressive neckgrooming), mutual upright posture, and chasing. Defensive behavior was also measured as the total number of seconds during which the rat subject showed immobile crouch posture, defensive upright posture, submissive-supine posture, and flight. Play fighting was not included in scoring, because its purpose is not to hurt others (Pellis \& Pellis, 1987; Pellis, Pellis, \& Foroud, 2005).

\section{Radioimmunoassay}

When rats were decapitated, trunk blood was collected and immediately placed on ice. Blood was centrifuged for $15 \mathrm{~min}$ at $2,500 \mathrm{rpm}$ at $4^{\circ} \mathrm{C}$. The serum was sampled and stored at $-20^{\circ} \mathrm{C}$ until used. These serum samples were processed to measure the concentrations of CORT and $\mathrm{T}$, using commercially available radioimmunoassay kits for CORT (Coat-A-Count Rat Corticosterone, DPC/Siemens, Oklahoma City, OK) and T (Coat-A-Count Total Testosterone, DPC/Siemens, Oklahoma City, OK).

\section{Receptor binding autoradiography}

Following the decapitation, brains were harvested, immediately frozen using dry ice, and stored in a $-70^{\circ} \mathrm{C}$ freezer until used. Coronal sections of the brains with $20-\mu \mathrm{m}$ thickness were collected from both the immobilized and nonimmobilized groups simultaneously (to ensure identical processing conditions between the groups) using a cryostat and then placed onto slides (Superfrost Plus, VWR, Westchester, PA). The collections of the sections started at $2.70 \mathrm{~mm}$ anterior from bregma (containing the PFC) and at $1.20 \mathrm{~mm}$ anterior from bregma (containing the striatum) (see Fig. 2). The PFC sections included the following regions of interest (ROIs): the prelimbic cortex (PrL), lateral orbital cortex (LO), ventral orbital cortex (VO), and infralimbic cortex (IL) in both hemispheres. The striatal sections included such ROIs as the dorsolateral caudate putamen (DLCPU), dorsomedial caudate putamen (DMCPU), core of the nucleus accumbens (ACBC), and the shell of the nucleus accumbens (ACBSH). All of these ROIs were referred to by our rat brain atlas (Paxinos \& Watson, 2005). Twelve slides with four PFC/striatal sections per slide were obtained from each rat subject. All slides were stored at $-70^{\circ} \mathrm{C}$ until autoradiographic experiments were ready to be run.

Autoradiography for assessing 5-HT1Br and D2r densities was performed on the basis of previously published protocols (Suzuki et al., 2010a; Suzuki, Han, \& Lucas, 2010b). The PFC sections were processed for assessing 5HT1Br binding, while the striatal sections were processed for assaying D2r binding. First, two representative slides containing four PFC sections and two other representative slides containing four striatal sections were selected. The PFC sections were prewashed twice with $50 \mathrm{mM}$ Tris- $\mathrm{HCl}$
Fig. 2 Schematic diagram of brain regions of interest. Red circles indicate approximate brain area sampled for each region during image analysis of autoradiographic experiments. a Prefrontal cortex (PFC). The regions analyzed in this diagram are the prelimbic cortex (PrL), ventral orbital cortex (VO), lateral orbital cortex (LO), and infralimbic cortex (IL). b Striatum. The regions analyzed in this diagram are the dorsolateral caudate putamen (DLCPU), the dorsomedial caudate putamen (DMCPU), the core of the nucleus accumbens (ACBC), and the shell of the nucleus accumbens (ACBSH)

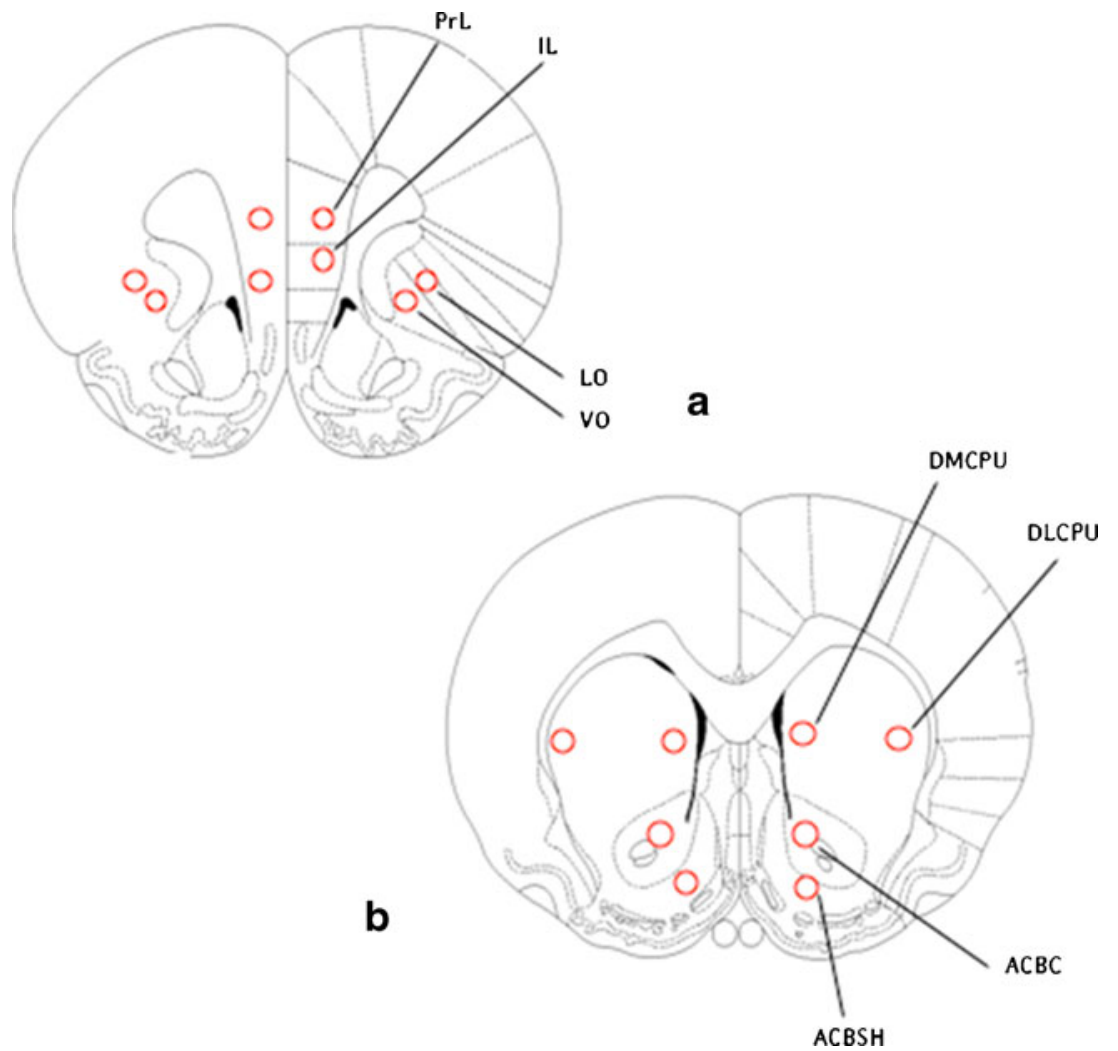


at $\mathrm{pH}$ 7.4. Then they were incubated for $120 \mathrm{~min}$ at room temperature in a buffer solution containing $170 \mathrm{mM}$ Tris- $\mathrm{HCl}$ (pH 7.4), $150 \mathrm{mM} \mathrm{NaCl}, 50 \mathrm{pM}$ $\left[{ }^{125} \mathrm{I}\right]$ cyanopindolol (a selective ligand for $5-\mathrm{HT} 1 \mathrm{Br}$ ), $100 \mathrm{nM}$ 8-OH-DPAT, and $30 \mu \mathrm{M}$ of isoproterenol. After the incubation, the PFC sections were rinsed twice for $5 \mathrm{~min}$ in the cold buffer solution (the same buffer solution as above, except for the ligand) and then rinsed for less than $5 \mathrm{~s}$ in $4^{\circ} \mathrm{C}$ double-distilled $\mathrm{H}_{2} \mathrm{O}$.

The striatal sections were incubated for $90 \mathrm{~min}$ at room temperature in a buffer solution that contained $50 \mathrm{mM}$ Tris$\mathrm{HCl}$ (pH 7.4), $120 \mathrm{mM} \mathrm{NaCl}, 5 \mathrm{mM} \mathrm{KCl}, 2 \mathrm{mM} \mathrm{CaCl}_{2}$, $1 \mathrm{mM} \mathrm{MgCl}_{2}, 0.20 \mathrm{nM}\left[{ }^{125} \mathrm{I}\right]$ sulpride (a selective ligand for $\mathrm{D} 2 \mathrm{r}$ ), and $50 \mathrm{nM}$ ketanserin. Following the incubation, the striatal sections were washed three times $(10 \mathrm{~min}$ per wash) in a cold 50-mM Tris- $\mathrm{HCl}(\mathrm{pH} 7.4)$, submerged in ice-cold double-distilled $\mathrm{H}_{2} \mathrm{O}$ for a final wash, and quickly removed.

Once all sections were dried, both the PFC and striatal sections were taped onto BioMax MR film (Kodak) and placed into a cassette. The PFC sections were exposed for either 4 or $12 \mathrm{~h}$, and the striatal sections were exposed for either 48 or $72 \mathrm{~h}$, depending on the experiment. The films were developed, and a relative intensity in each ROI was measured as the density of $5-\mathrm{HT} 1 \mathrm{Br}$ or D2r, using a calibration scale. To calculate the density of the target receptor more precisely, the background intensity of the film was subtracted from the intensity within ROI, following a previously established computation (Suzuki et al., 2010a, 2010b). All relative density values of ROI within each rat subject were then averaged. One rat subject was removed due to damage to the slides during processing.

\section{Statistical strategy}

All data were expressed as mean with standard error of the mean, unless otherwise noted. In order to test any differences in body weight between the immobilized and nonimmobilized groups, independent-samples $t$-tests were performed. Three-way ANOVAs were performed for testing interactions between immobilization stress exposure (exposure to immobilization or nonimmobilization), stressor length (1-day, 5-day, or 10-day immobilization sessions), and opponent size (smaller or larger), regarding aggressive behavior and serum CORT and T levels. Finally, because we found a large variability in receptor binding within the same stress exposure condition, we normalized density values in each of the 1-day, 5-day, and 10-day conditions by computing (density value of immobilized subject)/(mean density value of nonimmobilized control group) -1 . Subtracting 1 from the ratio set the mean of the control group to zero, which allowed us to easily interpret how much immobilized rats showed higher (if positive) or lower (if negative) receptor density of $5-\mathrm{HT} 1 \mathrm{Br} / \mathrm{D} 2 \mathrm{r}$ than did controls. After this normalization, one-sample $t$-tests were performed to test whether the ratio was significantly larger or smaller.

\section{Results}

Weights

There was no difference in body weight of stressed and nonstressed rats across days during the 1-day, 5-day, or 10-day exposure experiment plus the three follow-up behavioral tests (all $p$-values $>.05$ ). The trend of weight gain over days for each stress group is shown in Fig. 3.

\section{Aggressive behavior}

There was a main effect of stressor length on aggressive behavior. That is, regardless of being treated with an immobilization stress exposure, rats showed significantly more aggression when exposed to 5-day immobilization/nonimmobilization than did rats exposed to acute 1-day immobilization/nonimmobilization; furthermore, rats exposed to chronic 10-day immobilization/nonimmobilization showed significantly more aggression than did those in 1-day or 5day immobilization/nonimmobilization sessions, $F(2,106)=$ $32.21, p<.01$. In addition, there was a main effect of opponent size on aggressive behavior. Regardless of immobilization stress exposure and stressor length, rats screened against a larger opponent showed lower levels of aggression than did those screened against a smaller opponent, $F(1,106)=108, p<.01$.

There was also a two-way interaction effect between immobilization stress exposure and stressor length, $F(2$, 106 ) $=5.09, p<.01$ (see Fig. 4); regardless of the opponent size being screened against, 10-day immobilized rats showed significantly more aggression than did 10-day nonimmobilized controls, $t(106)=2.28, p<.01$; in contrast, 1 day immobilized rats showed less aggression than did 1-day nonimmobilized controls, $t(105)=3.25, p=.01$. It should be noted that there was the opposite effects of stress on aggressive behavior, depending on stressor length. In addition, this interaction effect remained significant across three time points: Figure 4 shows that, even after a week of recovery period from immobilization, 10-day immobilized rats maintained marginally higher levels of aggression than did 10-day nonimmobilized controls, $t(33)=2.01, p=.052$, while 1-day immobilized rats maintained significantly lower levels of aggression than did 1-day nonimmobilized controls, $t(33)=2.81, p<.01$. The other interaction effects were not significant. 

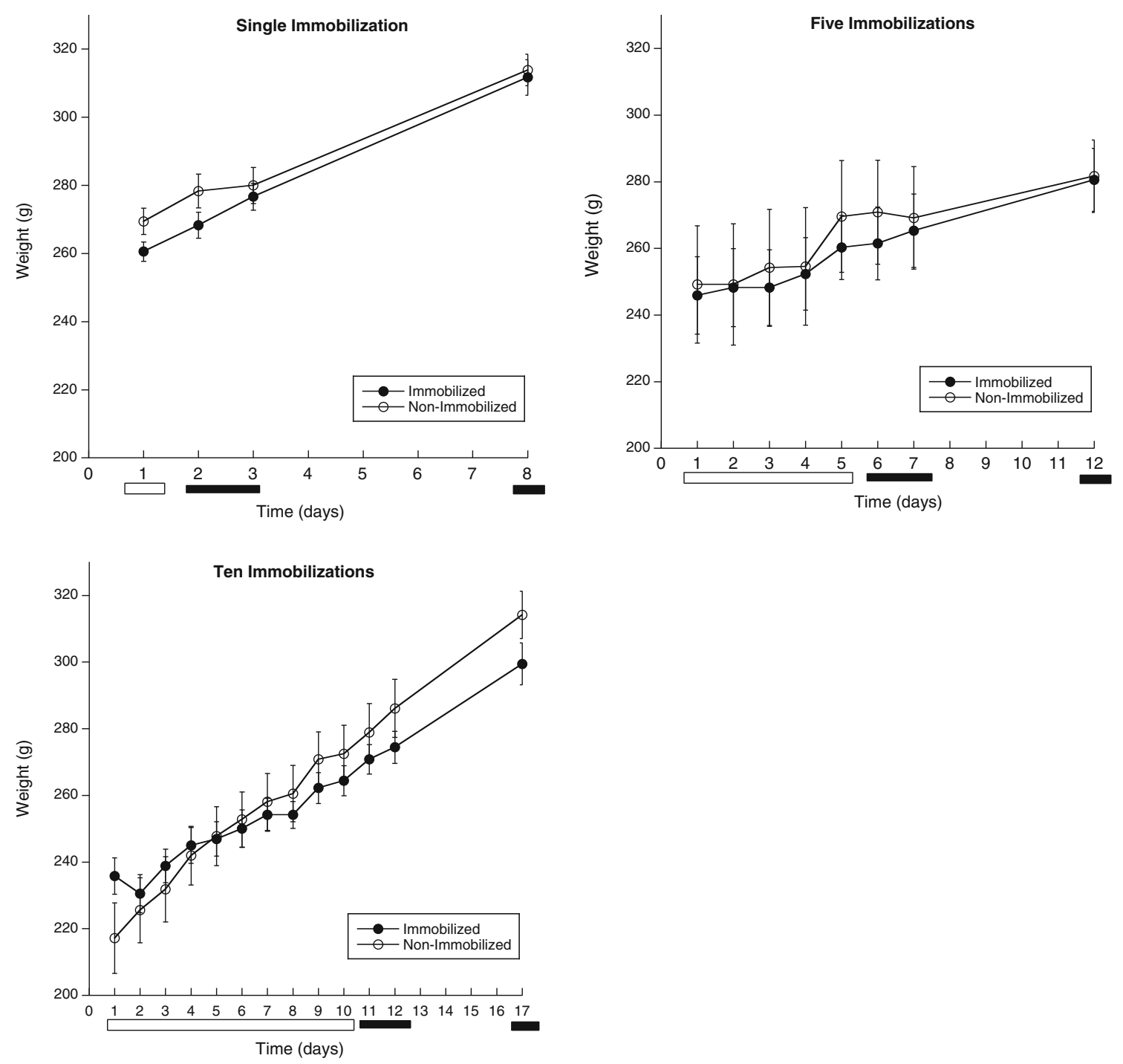

Fig. 3 Mean weights of subjects on each day of experiment for each group of animals undergoing either 1-day, 5-day, or 10-day immobilization. White bars indicate the immobilization portion of the experiment. Black bars indicate days of screening tests

\section{Corticosterone and testosterone}

Both CORT and T levels in serum were assayed after the last behavioral screening test was administered (i.e., 7 days after immobilization/nonimmobilization stress session[s]). While there was a significant interaction between immobilization stress exposure and stressor length on aggressive behavior across time (see Fig. 4), Fig. 5 shows that there were no effects of immobilization stress exposure, stressor length, and opponent size, as well as any possible interactions, on serum levels of CORT. However, all levels seemed to be higher than resting levels during nocturnal periods (indicated by a dotted line).

Rats exposed to immobilization stress, regardless of stressor length or opponent size, showed marginally higher levels of serum $\mathrm{T}$ than did nonimmobilized rats, $F(1,101)=$ $5.71, p=.05$, as is shown in Fig. 6. Also, rats undergoing a 1-day immobilization/nonimmobilization experiment showed significantly higher levels of serum $\mathrm{T}$ than did those undergoing 5- and 10-day immobilization/nonimmobilization experiments, $F(2,101)=7.27, p<.01$. All rats showed elevated levels of $\mathrm{T}$, as compared with resting levels during nocturnal periods (indicated by a dotted line).

\section{5- $\mathrm{HT}_{1 \mathrm{~B}}$ receptor binding in the $\mathrm{PFC}$}

Figure 7 indicates that no ratio of 5-HT1Br density in 1day immobilized rats versus 1-day non-immobilized rats was significant. When rats underwent 5-day immobilization sessions and then encountered smaller opponents, a negative ratio in the left $\mathrm{VO}, t(22)=-2.19, p<.05$, and a positive ratio in the right $\mathrm{VO}, t(22)=-2.63, p<.05$, were found. Among those that underwent 5-day immobilization sessions and were screened against larger opponents, three positive ratios of $5-\mathrm{HT} 1 \mathrm{Br}$ density were 


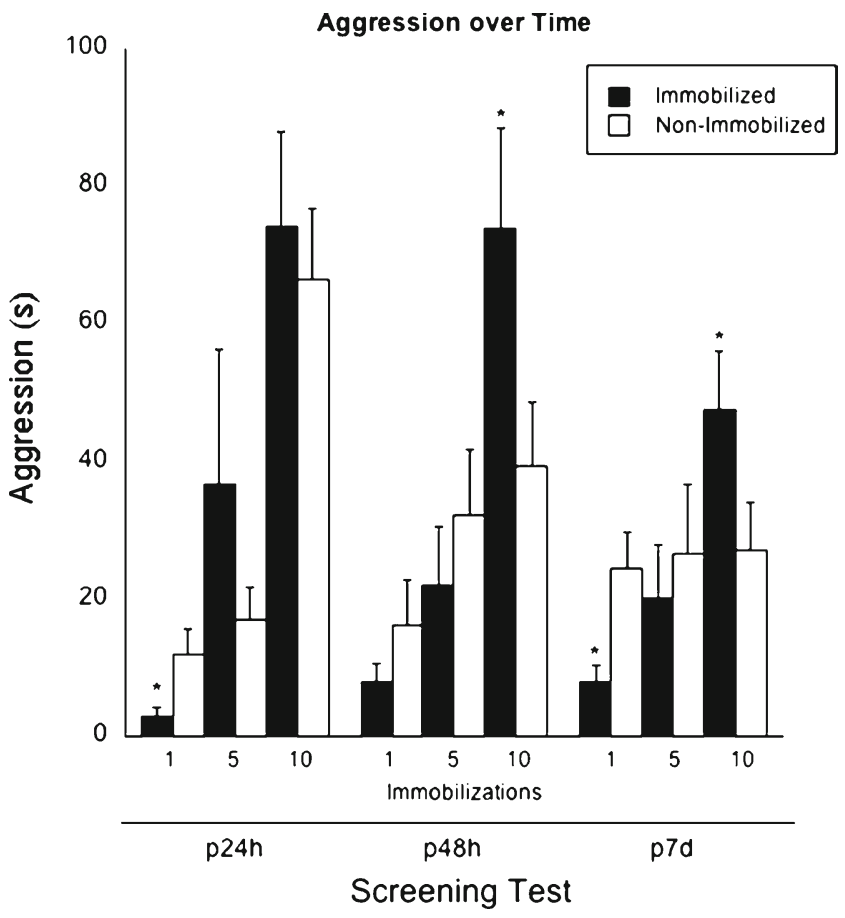

Fig. 4 Amount of aggressive behavior (in seconds) at each screening test comparing subjects exposed to 1-day, 5-day, or 10-day immobilization/nonimmobilization. Even after 1 week of recovery from immobilization, significant differences in aggression were still maintained. ${ }^{*} p<.05$, comparing immobilized and nonimmobilized subjects

found: the left PrL, $t(9)=2.62, p<.05$, left LO, $t(9)=$ $3.45, p<.01$, and right $\mathrm{VO}, t(9)=4.58, p<.01$. For those that underwent 10-day immobilization sessions and encountered smaller opponents, negative ratios were found in the right $\operatorname{PrL}, t(23)=-2.70, p<.05$, and in the right LO, $t$

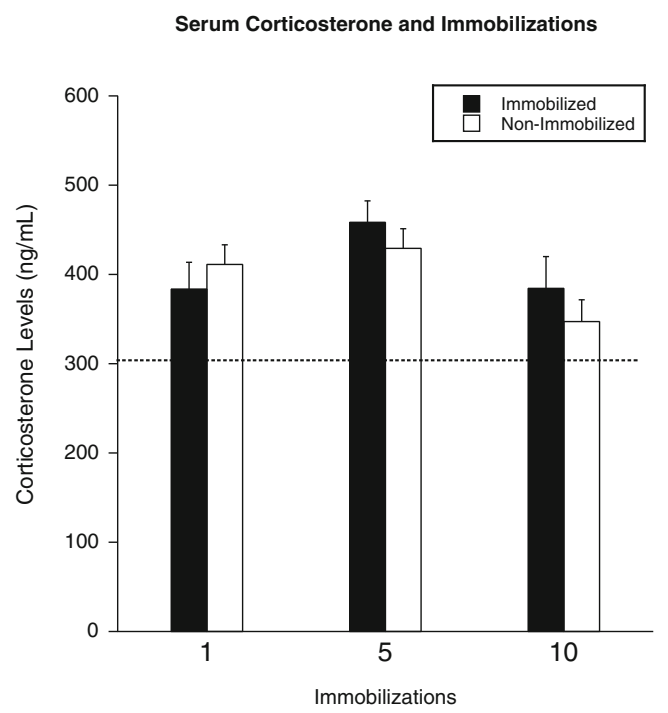

Fig. 5 Serum CORT levels of subjects exposed to 1-day, 5-day, or 10day immobilization/nonimmobilization. Results showed no difference in serum CORT levels between immobilized and nonimmobilized subjects. Dashed line indicates peak nocturnal CORT levels
Serum Testosterone and Immobilizations

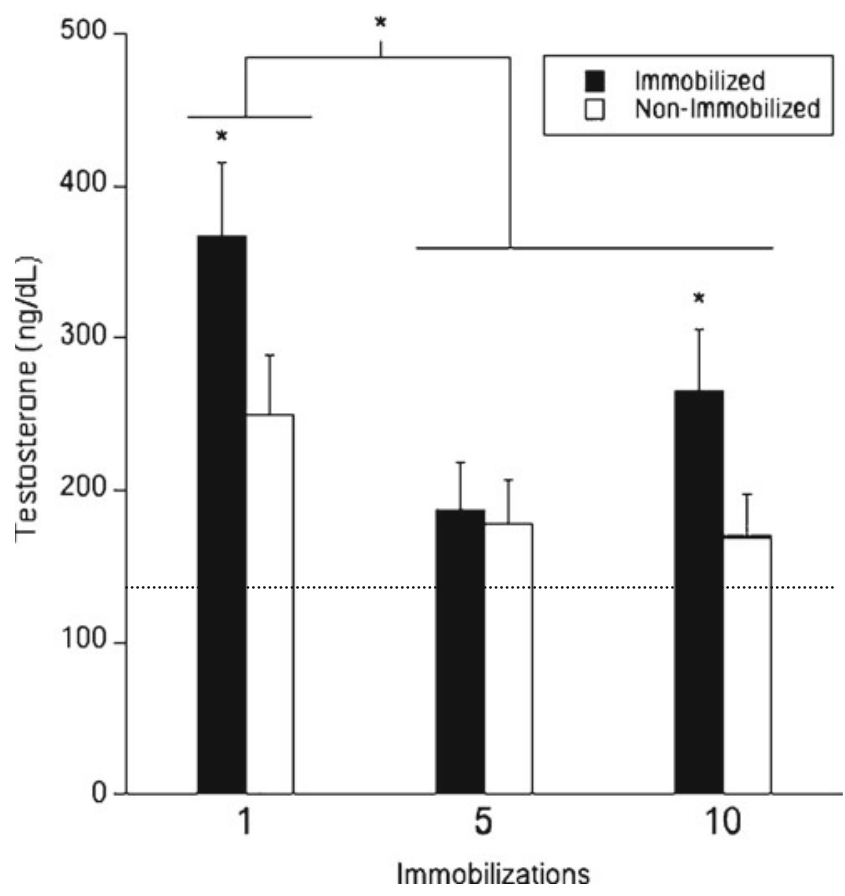

Fig. 6 Serum T levels of subjects exposed to 1-day, 5-day, or 10-day immobilization/nonimmobilization. Regardless of the length of exposure to immobilization, immobilized rats demonstrated an increase in T. Dashed line indicates basal nocturnal T levels. ${ }^{*} p<.05$, comparing immobilized and nonimmobilized subjects and comparing 1-day immobilization subjects with 5- and 10-day immobilization subjects

(23) $=-4.32, p<.01$. Finally, when rats underwent 10-day immobilization sessions and encountered larger opponents, significant positive ratios were found in the left PrL, $t(11)=$ $10.01, p<.01$, left LO, $t(11)=9.58, p<.01$, and right VO, $t$ $(11)=3.06, p<.05$.

Dopamine $\mathrm{D}_{2}$ receptor binding in the striatum

As is shown in Fig. 8, rats undergoing a 1-day immobilization session and encountering small opponents showed a significant positive ratio of $\mathrm{D} 2 \mathrm{r}$ density in the left ACBSH, $t$ $(22)=4.18, p<.01$, but a negative ratio in the right ACBSH, $t(22)=-4.76, p<.01$. However, when rats were screened against larger opponents under a 1-day immobilization session, there was only a significant negative ratio in the right ACBSH, $t(22)=-2.65, p<.05$. Rats undergoing 5and 10-day immobilization showed no significant ratio of D2r density, regardless of opponent size.

\section{Discussion}

The present study examined the behavioral, hormonal, and neurochemical consequences of stress-induced aggressive behavior. Our first aim was to investigate how 1-day, 5- 
Single Immobilization

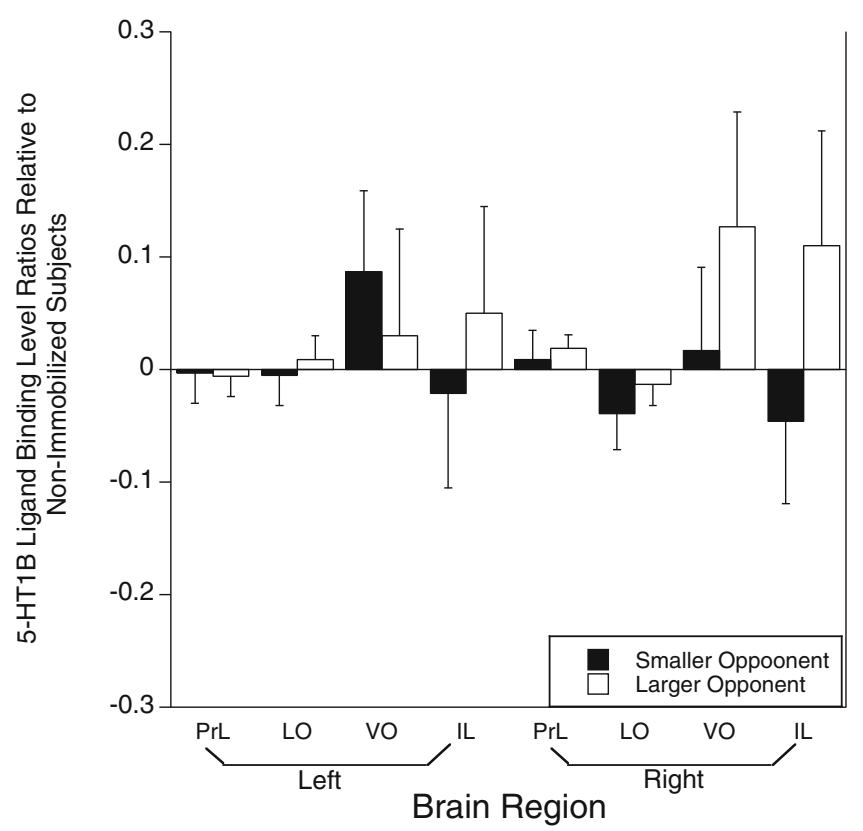

Ten Immobilizations

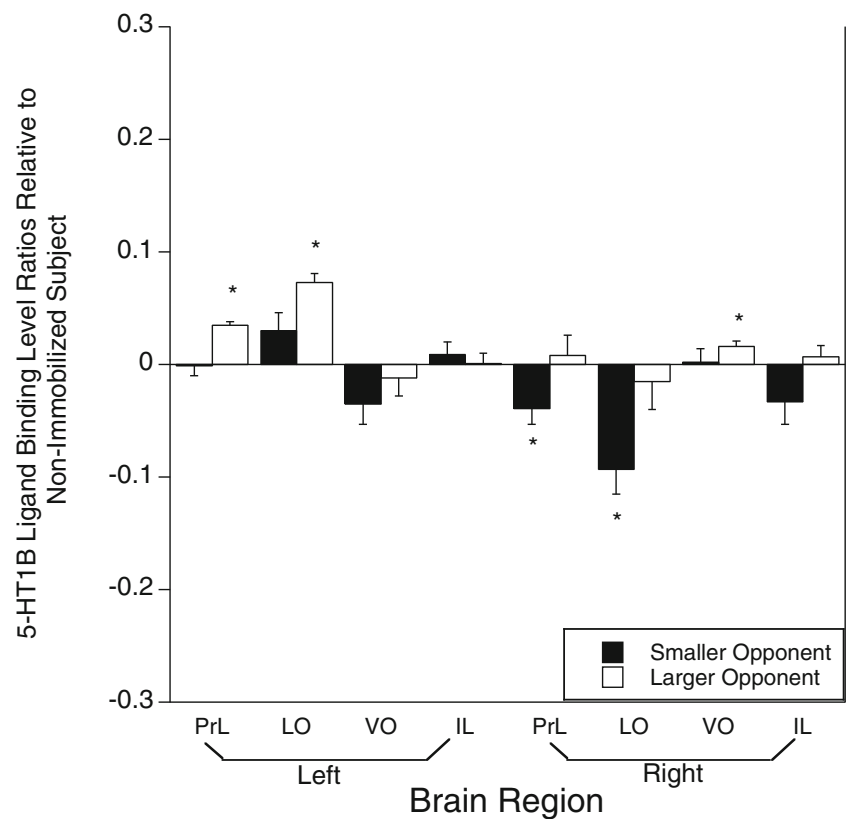

Fig. 7 Ratio of 5-HT1Br density of immobilized subjects relative to average 5-HT1Br density over nonimmobilized subjects across different immobilization lengths. PrL, prelimbic cortex; LO, lateral orbital

day, and 10-day exposure to immobilization stress would affect aggressive behavior. Unlike previous studies where stressed animal subjects were screened on the basis of their aggressive behavior against a random opponent (da Veiga et al., 2011; de Almeida \& Miczek, 2002; Fish et al., 1999; Wood et al., 2008; Wood et al., 2003), our study assessed longitudinal changes of aggressive behavior (across stress

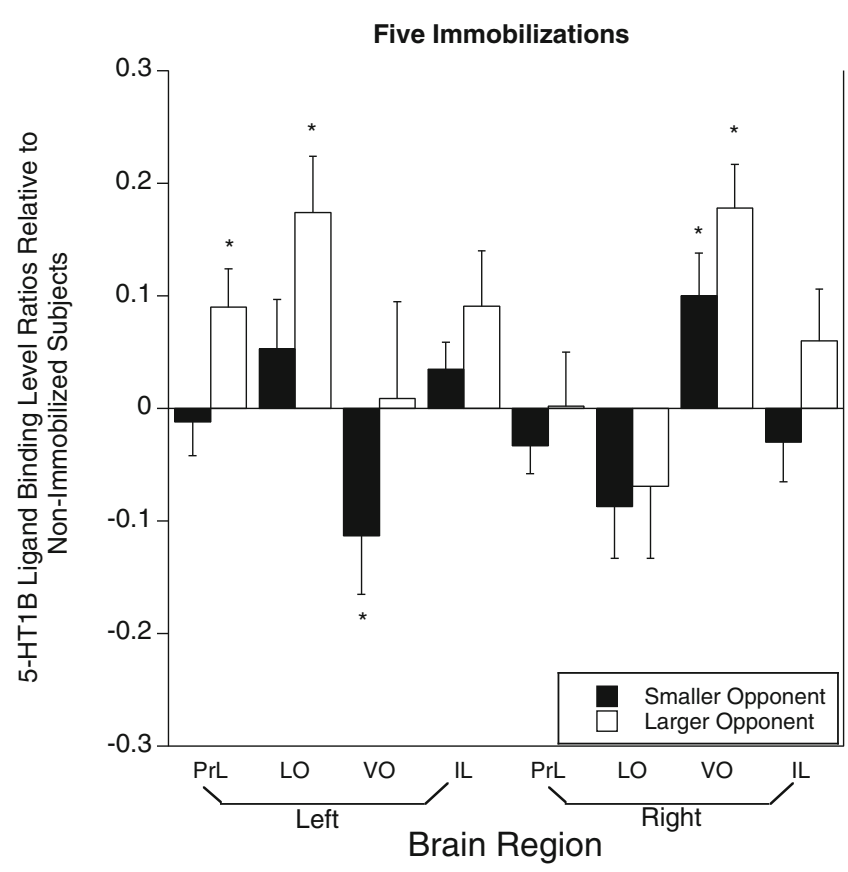

cortex; VO, ventral orbital cortex; IL, infralimbic cortex. ${ }^{*} p<.05$, as compared with the null hypothesis $($ ratio $=0$ )

phase and recovery phase) while controlling for the physical size of opponents, following various lengths of immobilization stress. Consistent with our hypothesis, chronic (10-day) immobilization stress increased aggressive behavior among rats over the course of the experiment. However, acute (1day) immobilization stress reduced aggressive behavior. These effects of immobilization on aggression did not 

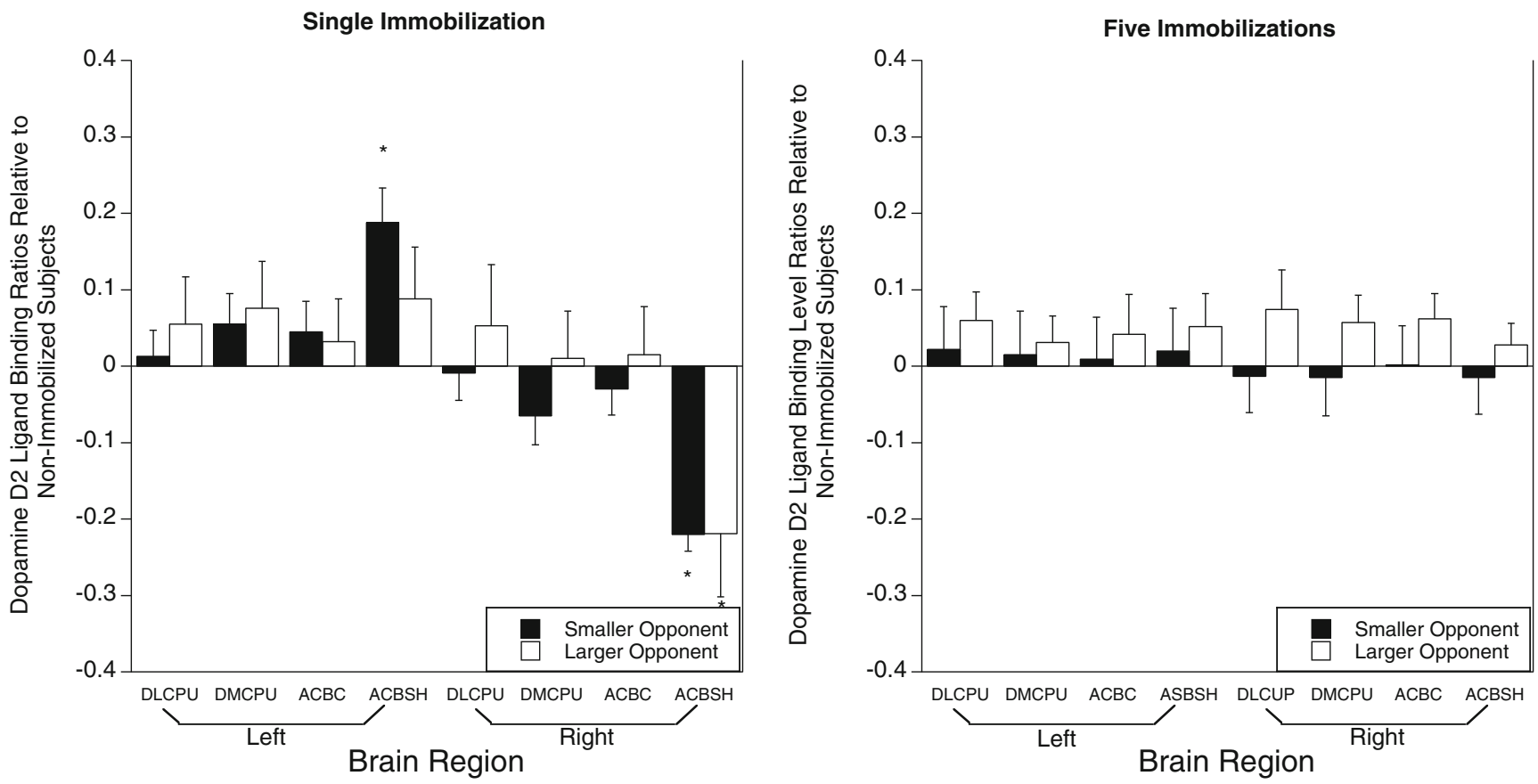

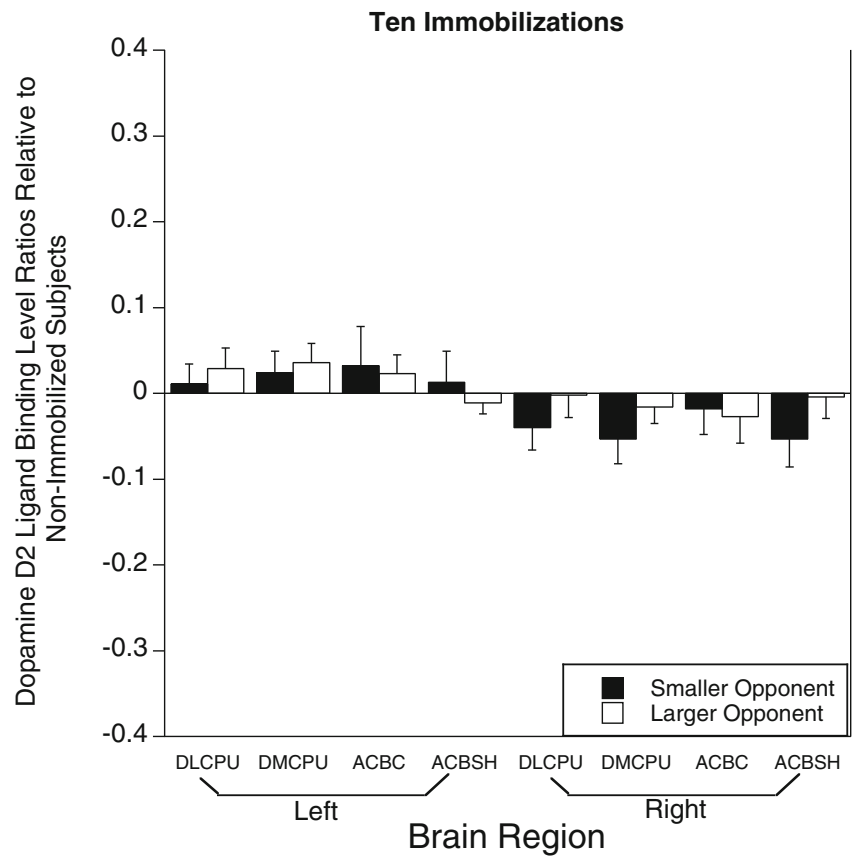

Fig. 8 Ratio of D2r density of immobilized subjects relative to average D2r density over nonimmobilized subjects across different immobilization lengths. DLCPU, dorsolateral caudate putamen; DMCPU,

change even after a recovery phase (e.g., 7 days after immobilization stress). In addition, it was found that stress exerted its effects on aggression regardless of opponent size.

Immobilization and body weight

Consistent with a previous finding (Lucas, Dragisic, Duwaerts, Swiatkowski, \& Suzuki, 2011), acute exposure dorsomedial caudate putamen; $\mathrm{ACBC}$, core of the nucleus accumbens; ACBSH, shell of the nucleus accumbens. ${ }^{*} p<.05$, as compared with the null hypothesis $($ ratio $=0$ )

to immobilization did not induce a change in weight. Interestingly, we did not find a decrease in weight gain even after chronic immobilization or even when a recovery period was taken into account. This result was inconsistent with those of previous studies using the restraint or immobilization paradigm (Benchimol de Souza et al., 2011; McLaughlin, Gomez, Baran, \& Conrad, 2007; Rabasa, Munoz-Abellan, Daviu, Nadal, \& Armario, 2011; Radley et al., 2008). This 
gap in effects of chronic stress on weight gain may be explained by the use of different methodologies, particularly stressor length. In other words, additional days of chronic immobilization (Benchimol de Souza et al., 2011; Radley et al., 2008) or a longer duration of immobilization per day (McLaughlin et al., 2007) may be required to see significant differences in weight gain between immobilized and nonimmobilized rats. On the other hand, our results raise the question of whether nonimmobilized rats were not stressed themselves. There is some evidence that intraspecific vocalizations may induce a stress response in animals recovering from immobilization stress, if they are recovering in the same room as immobilized rats (Lucas et al., 2007). Indeed, we let both immobilized and nonimmobilized rats in the same room during a recovery phase, and this might reduce the difference in weight gain between them.

\section{Effects of immobilization length on aggressive behavior}

Consistent with previous findings (Wood et al., 2008; Wood et al., 2003), acute exposure to stress decreased aggression, whereas repeated exposure to stress increased aggressive behavior. Therefore, a single exposure to immobilization may suppress aggressive behavior, while chronic exposure to immobilization may induce aggressive behavior. Moreover, our results revealed that stresssuppressed or stress-induced aggression lasted even for a recovery phase, at least 7 days after rats were removed from immobilization stress exposure. The duration of stress plays a crucial role in affecting aggressive behavior, and stress effects on aggression are not transient but relatively continuous.

It was somewhat surprising that the above effects of stress on aggression did not depend on the physical size of opponents, although, as was expected, rats screened against larger opponents showed lower levels of aggression, overall, than did those screened against smaller opponents. In general, animals are less likely to attack a larger conspecific opponent, simply because they have little chance of winning (Morrell, Lindstrom, \& Ruxton, 2005). In spite of this fact, our results showed that chronic immobilization stress escalated aggressive behavior not only toward small opponents (i.e., contests with high likelihood of winning), but also toward large opponents (i.e., contests with low likelihood of winning). These results may suggest that chronic stress impairs the ability to assess one's own chance of winning on the basis of social contexts, which might initiate "risky" aggressive behavior toward a larger opponent. While this is speculative, some preclinical studies have demonstrated that stressed animals change their fearful responses to contextual stimuli (Litvin et al., 2010; Wood et al., 2008) and increase risk-taking behavior (Llorente-Berzal et al., 2011; Toledo-Rodriguez \& Sandi, 2011; van Heerden, Russell,
Korff, Stein, \& Illing, 2010), both of which may result from "perception errors" (Morrell et al., 2005) in assessing danger/safety in social contexts. These perception errors might drive immobilized rats to attempt to defeat opponents, regardless of their chance of winning.

\section{Hormonal outcomes}

It was unexpected that there was no difference in CORT levels between immobilized and nonimmobilized rats. Note that levels of CORT across all groups were above peak nocturnal levels, suggesting that all rats in our study might have experienced some degree of stress. Across immobilized and nonimmobilized rats, CORT samples were collected immediately after the last behavioral screening test; thus, an encounter with an opponent might be one of the sources for their mild stress. Alternatively, some studies similarly have found that both stressed and nonstressed rats showed equally high levels of CORT (above basal levels) (Bowman, Maclusky, Diaz, Zrull, \& Luine, 2006; Wood et al., 2003); thus, stress may not necessarily elevate CORT levels under some circumstances.

In contrast to our CORT findings, however, a number of previous studies have demonstrated that stress increases CORT levels (Blanchard, Sakai, McEwen, Weiss, \& Blanchard, 1993; Blanchard et al., 1995; Lucas et al., 2004; Lucas et al., 2011; Lucas et al., 2007; Rabasa et al., 2011; Tamashiro et al., 2004). One possible reason explaining our CORT findings may be that nonimmobilized rats became as stressed as immobilized rats because they were housed individually through immobilization sessions and behavioral assessments. In fact, individually housed rodents show increased levels of CORT (Ferland \& Schrader, 2011; Frances et al., 2000) and a failure to return stress-elevated CORT levels to the baseline (Lucas et al., 2007). An alternative explanation for our CORT findings lies in the possibility that CORT levels in our study actually reflected social interactions with opponents, whereas effects of immobilization stress on CORT levels might subside. In this case, after our manipulations in stress exposure, both immobilized and nonimmobilized rats might have experienced dominance/social rewards or subordination/social aversion as a result of social interactions with opponents. According to previous studies, CORT levels can be elevated as a consequence of both victory and defeat in intermale aggression (Blanchard et al., 1993; Blanchard et al., 1995; Lucas et al., 2004; Tamashiro et al., 2004); in addition, there is no difference in CORT response between socially rewarding and aversive stimuli (Buwalda, Scholte, de Boer, Coppens, \& Koolhaas, 2012). These findings suggest that both positive and negative social experience can change CORT levels in a similar manner. Whatever the case may be, we did not measure CORT 
levels right before the first social interaction; thus, it is difficult to clarify why CORT levels did not differ between immobilized and nonimmmobilized rats in our study. However, despite these possible limitations to our study, our evidence still supports that aggression was induced by chronic immobilization stress.

Although both immobilized and nonimmobilized rats showed higher T levels than basal nocturnal levels (Leal \& Moreira, 1997), acute 1-day and chronic 10-day immobilization stress (but not 5-day immobilization stress) significantly elevated $\mathrm{T}$ levels, as compared with controls. Moreover, rats undergoing 1-day immobilization stress displayed the highest $\mathrm{T}$ levels, as well as the lowest levels of aggression, which was a surprising result. Therefore, while our results yielded the fact that immobilization stress elevated $\mathrm{T}$ levels, the increased levels of $\mathrm{T}$ seemed to be irrelevant to stress-induced aggression. Interestingly, some studies have reported that elevated $\mathrm{T}$ levels do not necessarily indicate high levels of aggression; for example, increased levels of $\mathrm{T}$ were not found in dominant rats (Blanchard et al., 1995; Monder, Sakai, Miroff, Blanchard, \& Blanchard, 1994; Tamashiro et al., 2004) or in aggressive rats that passively observed aggressive conflicts (Suzuki et al., 2010a; Suzuki \& Lucas, 2010). It is possible that elevated $\mathrm{T}$ levels are thus related to sex or age differences in aggressive behavior (Van Goozen, 2005), rather than stressinduced aggression.

\section{5-HT ${ }_{1 \mathrm{~B}}$ receptor density and stress-induced aggression}

The present study found that encounters with larger opponents following 5-day or 10-day immobilization stress upregulated 5-HT1Br densities in the left PrL, left LO, and right $\mathrm{VO}$. When rats were screened against small opponents, 5-day immobilization stress similarly up-regulated 5-HT1Br density in the right VO but down-regulated the density in the left VO. More importantly, when rats underwent 10-day immobilization stress and were screened against small opponents, we found specific markers of 5-HT1Br density alterations: low 5-HT1Br densities in the right PrL and right LO. In contrast, acute 1-day immobilization stress did not alter 5$\mathrm{HT} 1 \mathrm{Br}$ density in the PFC. As was summarized previously, 10-day immobilization stress induced aggression, whereas 1-day immobilization stress suppressed it. Therefore, taken together, $5-\mathrm{HT} 1 \mathrm{Br}$ in the PFC seems to be involved in stress-induced aggression, but not stress-suppressed aggression. In particular, low prelimbic and orbitolateral 5-HT1Br densities of the right hemisphere seem to contribute to stress-induced aggression, since these changes were specific to 10-day immobilization stress.

A number of studies have addressed the important roles of $5 \mathrm{HT} 1 \mathrm{Br}$ in both stress susceptibility (Bouwknecht, van der Gugten, et al., 2001b; Groenink, van Bogaert, van der
Gugten, Oosting, \& Olivier, 2003) and aggressive behavior (Bouwknecht, Hijzen, et al., 2001a; de Boer \& Koolhaas, 2005; Olivier \& van Oorschot, 2005; Saudou et al., 1994; Suzuki et al., 2010a, 2010b). To our knowledge, no stress research has focused on cortical 5-HT1Br density. But it has been suggested that chronic stress decreases hippocampal 5HT1Br binding (Mendelson \& McEwen, 1992) and hippocampal 5-HT ${ }_{1 \mathrm{~B}}$ mRNA expression (Lopez et al., 1997). Our findings added that chronic stress down-regulates 5-HT1Br binding not only in the hippocampus, but also in some subregions of the PFC, such as the prelimbic and orbitolateral cortices.

Decreased 5-HT1Br density is also a possible marker for escalated aggressive behavior. Pharmacological research has consistently demonstrated that aggression is reduced by 5 HT1Br agonists (Bannai, Fish, Faccidomo, \& Miczek, 2007; de Almeida \& Miczek, 2002; Fish et al., 1999). Thus, if the stimulation of $5-\mathrm{HT} 1 \mathrm{Br}$ (acted by $5-\mathrm{HT} 1 \mathrm{Br}$ agonists) inhibits aggressive behavior, it is reasonable to expect that the blockage of 5-HT1Br, which may be analogous to low availability of 5-HT1Br or low 5-HT1Br densities, increases aggressive behavior. More interestingly, the microinjection of 5-HT1Br agonists into the PFC decreases aggressive behavior (Centenaro et al., 2008; da Veiga et al., 2011; De Almeida et al., 2006; Veiga, Miczek, Lucion, \& Almeida, 2007). Therefore, our findings suggest the possibility that chronic stress down-regulates $5-\mathrm{HT} 1 \mathrm{Br}$ densities in the prelimbic and orbitolateral cortices of the right hemisphere, which, in turn, escalates aggressive behavior (Lopez et al., 1997), although further research is needed to test this hypothesis.

\section{Dopamine $\mathrm{D}_{2}$ receptor density and stress-suppressed} aggression

In contrast to our results of 5-HT1Br binding analysis, only 1-day immobilization stress altered D2r density in the striatum, and no change in striatal D2r density was found under 5- and 10-day immobilization stress. These results suggest that D2r may contribute to stress-suppressed aggression, but not stress-induced aggression. Specifically, rats undergoing 1-day immobilization stress showed a decrease in D2r density in the right ACBSH whenever they were screened against small or large opponents. When they repeatedly encountered small opponents, they additionally showed high D2r density in the left ACBSH. Therefore, the bilateral, accumbal D2r may function as stress-suppressed aggression. It is also interesting that acute immobilization stress asymmetrically altered D2r densities in the ACBSH (i.e., the upregulation of $\mathrm{D} 2 \mathrm{r}$ in the left side and the downregulation of $\mathrm{D} 2 \mathrm{r}$ in the right side). It was reported that normal young rats show asymmetric densities of D2r in the nucleus accumbens (with higher density in the left than in the right) 
(Giardino, 1996), and lateralized dopaminergic activity in the brain may be associated with stress responsiveness (Carlson, Fitzgerald, Keller, \& Glick, 1991; Carlson \& Glick, 1991). But implications in the lateralized alterations in accumbal D2r densities are still under investigation.

While we found that only acute immobilization stress changed D2r binding within striatum, another study (Lucas et al., 2007) reported that rats undergoing acute immobilization did not show any changes in D2r densities in the striatum. Instead, chronically immobilized rats showed an increase in D2r density in the ACBSH when they were individually housed. These differences in outcomes may be due to differences in methodolology, including additionally administered repeated behavioral assessments (i.e., social interactions with opponents) following immobilization stress. It is possible that social interactions following acute stress exposure may serve as "extra stressors" and alter accumbal D2r density, whereas social interactions following chronic stress exposure may recover stress levels due to immobilization and return accumbal D2 $r$ density to the baseline. Indeed, this research group found that a pairhousing environment following immobilization stress could recover stress levels among immobilized rats.

The relationship between accumbal D2r and stresssuppressed aggression remains unclear. It was previously reported that down-regulated D2r densities in the bilateral ACBSH were found among potentially aggressive rats that were passively exposed to intermale aggression (Suzuki et al., 2010a). Thus, the upregulation of D2r in the left ACBSH, which was found among rats undergoing acute immobilization stress screened against small opponents, may solely contribute to stress-suppressed aggression. Consistent with this possibility, the administration of a $\mathrm{D} 2 \mathrm{r}$ agonist into the ACBSH, which may be analogous to high D2r density, facilitates pair bond formation (Aragona et al., 2006). Assuming that social bonding is prosocial behavior, as opposed to aggressive behavior, it is possible that the upregulation of $\mathrm{D} 2 \mathrm{r}$ may serve to reduce aggressive behavior toward others.

\section{Conclusions}

The present study examined whether varying levels of exposure to immobilization influenced aggressive behavior of rats, while investigating stress-related changes in weight gain, CORT, T, 5-HT1Br binding, and D2r binding of aggression. Acute immobilization resulted in stress-suppressed aggression, whereas chronic immobilization leads to stressinduced aggression, and these stress effects lasted even after 7 days of recovery from immobilization stress. Also, the stress effects were found despite the subject's chance of winning over opponents. This may suggest that chronic immobilization escalates not only normative aggressive behavior (i.e., attacking small opponents, with a great chance of winning) but also "risky" aggressive behavior (i.e., attacking large opponents, with a little chance of winning). While immobilization stress exposure did not change body weight and CORT levels, acute and chronic immobilization stress elevated T levels. Finally, acute immobilization stress altered $\mathrm{D} 2 \mathrm{r}$ densities in the bilateral ACBSH asymmetrically, and chronic immobilization stress up- and down-regulated 5-HT1Br densities in various subregions of the PFC, such as the right prelimbic and orbitolateral cortices. These neurochemical alterations may contribute to stress-suppressed or stress-induced aggression, respectively.

Author note This study was supported by a Carbon scholarship (L.R.Y.) and Loyola University Chicago Research Support grants (H.S.,L.R.L.).

\section{References}

Aragona, B. J., Liu, Y., Yu, Y. J., Curtis, J. T., Detwiler, J. M., Insel, T. R., \& Wang, Z. (2006). Nucleus accumbens dopamine differentially mediates the formation and maintenance of monogamous pair bonds. Nature Neuroscience, 9, 133139. doi: $10.1038 / \mathrm{nn} 1613$

Bannai, M., Fish, E. W., Faccidomo, S., \& Miczek, K. A. (2007). Antiaggressive effects of agonists at 5-HT1B receptors in the dorsal raphe nucleus of mice. Psychopharmacology, 193, 295-304. doi:10.1007/s00213-007-0780-5

Benchimol de Souza, D., Silva, D., Marinho Costa Silva, C., Barcellos Sampaio, F. J., Silva Costa, W., \& Martins Cortez, C. (2011). Effects of immobilization stress on kidneys of Wistar male rats: A morphometrical and stereological analysis. Kidney \& Blood Pressure Research, 34, 424-429. doi: $10.1159 / 000328331$

Blanchard, D. C., \& Blanchard, R. J. (1990). Behavioral correlates of chronic dominance-subordination relationships of male rats in a seminatural situation. Neuroscience and Biobehavioral Reviews, 14, 455-462.

Blanchard, D. C., Sakai, R. R., McEwen, B., Weiss, S. M., \& Blanchard, R. J. (1993). Subordination stress: Behavioral, brain, and neuroendocrine correlates. Behavioural Brain Research, 58, 113-121.

Blanchard, D. C., Spencer, R. L., Weiss, S. M., Blanchard, R. J., Mcewen, B., \& Sakai, R. R. (1995). Visible burrow system as a model of chronic social stress: Behavioral and neuroendocrine correlates. Psychoneuroendocrinology, 20, 117-134.

Bouwknecht, J. A., Hijzen, T. H., van der Gugten, J., Maes, R. A., Hen, R., \& Olivier, B. (2001a). Absence of 5-HT(1B) receptors is associated with impaired impulse control in male 5-HT(1B) knockout mice. Biological Psychiatry, 49, 557-568.

Bouwknecht, J. A., van der Gugten, J., Hijzen, T. H., Maes, R. A., Hen, R., \& Olivier, B. (2001b). Corticosterone responses in 5-HT1B receptor knockout mice to stress or 5-HT1A receptor activation are normal. Psychopharmacology, 153, 484-490.

Bowman, R. E., Maclusky, N. J., Diaz, S. E., Zrull, M. C., \& Luine, V. N. (2006). Aged rats: Sex differences and responses to chronic stress. Brain Research, 1126, 156-166. doi:10.1016/j.brainres. 2006.07.047

Buwalda, B., Scholte, J., de Boer, S. F., Coppens, C. M., \& Koolhaas, J. M. (2012). The acute glucocorticoid stress response does not differentiate between rewarding and aversive social stimuli in rats. 
Hormones and Behavior, 61, 218-226. doi:10.1016/j.yhbeh. 2011.12.012

Carlson, J. N., Fitzgerald, L. W., Keller, R. W., Jr., \& Glick, S. D. (1991). Side and region dependent changes in dopamine activation with various durations of restraint stress. Brain Research, 550, 313-318. doi:10.1016/0006-8993(91)91333-V

Carlson, J. N., \& Glick, S. D. (1991). Brain laterality as a determinant of susceptibility to depression in an animal-model. Brain Research, 550, 324-328.

Centenaro, L. A., Vieira, K., Zimmermann, N., Miczek, K. A., Lucion, A. B., \& de Almeida, R. M. (2008). Social instigation and aggressive behavior in mice: Role of 5-HT1A and 5-HT1B receptors in the prefrontal cortex. Psychopharmacology, 201, 237-248. doi:10.1007/s00213-008-1269-6

Craig, I. W. (2007). The importance of stress and genetic variation in human aggression. Bioessays, 29, 227-236. doi:10.1002/bies.20538

da Veiga, C. P., Miczek, K. A., Lucion, A. B., \& de Almeida, R. M. (2011). Social instigation and aggression in postpartum female rats: Role of 5-Ht1A and 5-Ht1B receptors in the dorsal raphe nucleus and prefrontal cortex. Psychopharmacology, 213, 475487. doi:10.1007/s00213-010-2083-5

de Almeida, R. M. M., Ferrari, P. F., Parmigiani, S., \& Miczek, K. A. (2005). Escalated aggressive behavior: Dopamine, serotonin and GABA. European Journal of Pharmacology, 526, 51-64. doi:10.1016/j.ejphar.2005.10.004

de Almeida, R. M. M., \& Miczek, K. A. (2002). Aggression escalated by social instigation or by discontinuation of reinforcement ("frustration") in mice: Inhibition by anpirtoline. A 5-HT1B receptor agonist. Neuropsychopharmacology, 27, 171-181.

De Almeida, R. M. M., Rosa, M. M., Santos, D. M., Saft, D. M., Benini, Q., \& Miczek, K. A. (2006). 5-HT(1B) receptors, ventral orbitofrontal cortex, and aggressive behavior in mice. Psychopharmacology, 185, 441-450. doi:10.1007/s00213-006-0333-3

de Boer, S. F., \& Koolhaas, J. M. (2005). 5-HT1A and 5-HT1B receptor agonists and aggression: A pharmacological challenge of the serotonin deficiency hypothesis. European Journal of Pharmacology, 526, 125-139.

Delville, Y., Melloni, R. H., Jr., \& Ferris, C. F. (1998). Behavioral and neurobiological consequences of social subjugation during puberty in golden hamsters. Journal of Neuroscience, 18, 26672672.

Eichelman, B., \& Barchas, J. (1975). Facilitated shock-induced aggression following antidepressive medication in the rat. Pharmacology Biochemistry and Behavior, 3, 601-604. doi:10.1016/0091-3057 (75) $90180-\mathrm{X}$

Ferland, C. L., \& Schrader, L. A. (2011). Cage mate separation in pairhoused male rats evokes an acute stress corticosterone response. Neuroscience Letters, 489, 154-158. doi:10.1016/j.neulet. 2010.12.006

Fish, E. W., Faccidomo, S., \& Miczek, K. A. (1999). Aggression heightened by alcohol or social instigation in mice: Reduction by the 5-HT(1B) receptor agonist CP-94,253. Psychopharmacology, 146, 391-399. doi:10.1007/PL00005484

Frances, H., Graulet, A., Debray, M., Coudereau, J. P., Gueris, J., \& Bourre, J. M. (2000). Morphine-induced sensitization of locomotor activity in mice: Effect of social isolation on plasma corticosterone levels. Brain Research, 860, 136-140. doi:10.1016/ S0006-8993(00)0205-39

Giardino, L. (1996). Right-left asymmetry of D1- and D2-receptor density is lost in the basal ganglia of old rats. Brain Research, 720, 235-238. doi:10.1016/0006-8993(96)00144-8

Groenink, L., van Bogaert, M. J., van der Gugten, J., Oosting, R. S., \& Olivier, B. (2003). 5-HT1A receptor and 5-HT1B receptor knockout mice in stress and anxiety paradigms. Behavioural Pharmacology, 14, 369-383. doi:10.1097/01.fbp.0000087737.21047.75
Jacobson, L., \& Sapolsky, R. (1991). The role of the hippocampus in feedback regulation of the hypothalamic-pituitary-adrenocortical axis. Endocrine Reviews, 12, 118-134.

Kruk, M. R., Halasz, J., Meelis, W., \& Haller, J. (2004). Fast positive feedback between the adrenocortical stress response and a brain mechanism involved in aggressive behavior. Behavioral Neuroscience, 118, 1062-1070. doi:10.1037/0735-7044.118.5.1062

Leal, A. M. O., \& Moreira, A. C. (1997). Daily variation of plasma testosterone, androstenedione, and corticosterone in rats under food restriction. Hormones and Behavior, 31, 97-100. doi:10.1006/hbeh.1997.1321

Litvin, Y., Tovote, P., Pentkowski, N. S., Zeyda, T., King, L. B., Vasconcellos, A. J., . . . Blanchard, R. J. (2010). Maternal separation modulates short-term behavioral and physiological indices of the stress response. Hormones and Behavior, 58, 241-249. doi:10.1016/j.yhbeh.2010.03.010

Llorente-Berzal, A., Fuentes, S., Gagliano, H., Lopez-Gallardo, M., Armario, A., Viveros, M. P., \& Nadal, R. (2011). Sex-dependent effects of maternal deprivation and adolescent cannabinoid treatment on adult rat behaviour. Addiction Biology, 16, 624-637. doi:10.1111/j.1369-1600.2011.00318.x

Lopez, J. F., Vazquez, D. M., Chalmers, D. T., \& Watson, S. J. (1997). Regulation of 5-HT receptors and the hypothalamic-pituitaryadrenal axis. Implications for the neurobiology of suicide. Annals of the New York Academy of Sciences, 836, 106-134.

Lucas, L. R., Celen, Z., Tamashiro, K. L., Blanchard, R. J., Blanchard, D. C., Markham, C., . . . McEwen, B. S. (2004). Repeated exposure to social stress has long-term effects on indirect markers of dopaminergic activity in brain regions associated with motivated behavior. Neuroscience, 124, 449-457. doi:10.1016/ j.neuroscience.2003.12.009

Lucas, L. R., Dragisic, T., Duwaerts, C. C., Swiatkowski, M., \& Suzuki, H. (2011). Effects of recovery from immobilization stress on striatal preprodynorphin- and kappa opioid receptor-mRNA levels of the male rat. Physiology \& Behavior, 104, 972-980. doi:10.1016/ j.physbeh.2011.06.017

Lucas, L. R., Wang, C. J., McCall, T. J., \& McEwen, B. S. (2007). Effects of immobilization stress on neurochemical markers in the motivational system of the male rat. Brain Research, 1155, 108115. doi:10.1016/j.brainres.2007.04.063

Malick, J. B. (1979). The pharmacology of isolation-induced aggressive behavior in mice. Current Developments in Psychopharmacology, 5, 1-27.

McLaughlin, K. J., Gomez, J. L., Baran, S. E., \& Conrad, C. D. (2007). The effects of chronic stress on hippocampal morphology and function: An evaluation of chronic restraint paradigms. Brain Research, 1161, 56-64. doi:10.1016/j.brainres.2007.05.042

Mendelson, S. D., \& McEwen, B. S. (1992). Autoradiographic analyses of the effects of adrenalectomy and corticosterone on 5-HT1A and 5-HT1B receptors in the dorsal hippocampus and cortex of the rat. Neuroendocrinology, 55, 444-450.

Monder, C., Sakai, R. R., Miroff, Y., Blanchard, D. C., \& Blanchard, R. J. (1994). Reciprocal changes in plasma corticosterone and testosterone in stressed male rats maintained in a visible burrow system: Evidence for a mediating role of testicular 11 betahydroxysteroid dehydrogenase. Endocrinology, 134, 1193-1198.

Morrell, L. J., Lindstrom, J., \& Ruxton, G. D. (2005). Why are small males aggressive? Proceedings of the Royal Society B, 272, 12351241. doi:10.1098/Rspb.2005.3085

Olivier, B., \& van Oorschot, R. (2005). 5-HT1B receptors and aggression: A review. European Journal of Pharmacology, 526, 207217. doi:10.1016/j.ejphar.2005.09.066

Olivier, B., \& Young, L. J. (2002). Animal models of aggression. In K. L. Davis, D. Charney, J. T. Coyle, \& C. Nemeroff (Eds.), Neuropsychopharmacology: The fifth generation of progress (pp. 1699 1708). Philadelphia: Lippincott Williams \& Wilkins. 
Paxinos, G., \& Watson, C. (2005). The rat brain in stereotaxic coordinates (5th ed.). San Diego, CA: Elsevier.

Pellis, S. M., \& Pellis, V. C. (1987). Play-fighting differs from serious fighting in both target of attack and tactics of fighting in the laboratory rat rattus norvegicus. Aggressive Behavior, 13, 227 242.

Pellis, S. M., Pellis, V. C., \& Foroud, A. (2005). Play fighting: Aggression, affiliation, and the development of nuanced social skills. In R. E. Tremblay, W. W. Hartup, \& J. Archer (Eds.), Developmental origins of aggression (pp. 47-62). New York: Guilford.

Rabasa, C., Munoz-Abellan, C., Daviu, N., Nadal, R., \& Armario, A. (2011). Repeated exposure to immobilization or two different footshock intensities reveals differential adaptation of the hypothalamic-pituitary-adrenal axis. Physiology \& Behavior, 103, 125-133. doi:10.1016/j.physbeh.2011.02.022

Rada, R. T., Kellner, R., \& Winslow, W. W. (1976). Plasma testosterone and aggressive behavior. Psychosomatics, 17, 138-142.

Radley, J. J., Rocher, A. B., Rodriguez, A., Ehlenberger, D. B., Dammann, M., McEwen, B. S., . . . Hof, P. R. (2008). Repeated stress alters dendritic spine morphology in the rat medial prefrontal cortex. Journal of Comparative Neurology, 507, 1141-1150. doi:10.1002/cne.21588

Saudou, F., Amara, D. A., Dierich, A., LeMeur, M., Ramboz, S., Segu, L., . . . Hen, R. (1994). Enhanced aggressive behavior in mice lacking 5-HT1B receptor. Science, 265, 1875-1878.

Suzuki, H., Han, S. D., \& Lucas, L. R. (2010a). Chronic passive exposure to aggression decreases $\mathrm{D}(2)$ and 5 -HT(1B) receptor densities. Physiology \& Behavior, 99, 562-570. doi:10.1016/ j.physbeh.2010.01.018

Suzuki, H., Han, S. D., \& Lucas, L. R. (2010b). Increased 5-HT1B receptor density in the basolateral amygdala of passive observer rats exposed to aggression. Brain Research Bulletin, 83, 38-43. doi:10.1016/j.brainresbull.2010.06.007

Suzuki, H., \& Lucas, L. R. (2010). Chronic passive exposure to aggression escalates aggressiveness of rat observers. Aggressive Behavior, 36, 54-66. doi:10.1002/Ab.20333

Tamashiro, K. L., Nguyen, M. M., Fujikawa, T., Xu, T., Yun Ma, L., Woods, S. C., \& Sakai, R. R. (2004). Metabolic and endocrine consequences of social stress in a visible burrow system. Physiology \& Behavior, 80, 683-693. doi:10.1016/j.physbeh.2003.12.002
Tamashiro, K. L., Nguyen, M. M., \& Sakai, R. R. (2005). Social stress: From rodents to primates. Frontiers in Neuroendocrinology, 26, 27-40. doi:10.1016/j.yfrne.2005.03.001

Toledo-Rodriguez, M., \& Sandi, C. (2011). Stress during adolescence increases novelty seeking and risk-taking behavior in male and female rats. Frontiers in Behavioral Neuroscience, 5, 17. doi:10.3389/fnbeh.2011.00017

Valzelli, L. (1985). Animal models of behavioral pathology and violent aggression. Methods and Findings in Experimental and Clinical Pharmacology, 7, 189-193.

van Erp, A. M., \& Miczek, K. A. (2000). Aggressive behavior, increased accumbal dopamine, and decreased cortical serotonin in rats. Journal of Neuroscience, 20, 9320-9325.

Van Goozen, S. H. M. (Ed.). (2005). Hormones and the developmental origins of aggression. New York: Guilford.

van Heerden, J. H., Russell, V., Korff, A., Stein, D. J., \& Illing, N. (2010). Evaluating the behavioural consequences of early maternal separation in adult $\mathrm{C} 57 \mathrm{BL} / 6$ mice; the importance of time. Behavioural Brain Research, 207, 332-342. doi:10.1016/ j.bbr.2009.10.015

Veiga, C. P., Miczek, K. A., Lucion, A. B., \& Almeida, R. M. (2007). Effect of 5-HT1B receptor agonists injected into the prefrontal cortex on maternal aggression in rats. Brazilian Journal of Medical and Biological Research, 40, 825-830. doi:10.1590/S0100879X2007000600012

Wommack, J. C., \& Delville, Y. (2003). Repeated social stress and the development of agonistic behavior: Individual differences in coping responses in male golden hamsters. Physiology \& Behavior, 80, 303-308. doi:10.1016/j.physbeh.2003.08.002

Wood, G. E., Norris, E. H., Waters, E., Stoldt, J. T., \& McEwen, B. S. (2008). Chronic immobilization stress alters aspects of emotionality and associative learning in the rat. Behavioral Neuroscience, 122, 282-292. doi:10.1037/0735-7044.122.2.282

Wood, G. E., Young, L. T., Reagan, L. P., \& McEwen, B. S. (2003). Acute and chronic restraint stress alter the incidence of social conflict in male rats. Hormones and Behavior, 43, 205-213. doi:10.1016/S0018-506X(02)00026-0

Zebrowska-Lupina, I., Ossowska, G., \& Klenk-Majewska, B. (1991). Chronic stress reduces fighting behavior of rats: The effect of antidepressants. Pharmacology Biochemistry and Behavior, 39, 293-296. doi:10.1016/0091-3057(91)90182-2 